\section{Ultrasonographic atlas of splenic lesions}

\author{
Gayoung Choi ${ }^{1,2}$, Kyeong Ah Kim', Jinhwan Lee ${ }^{3}$, Yang Shin Park', Jongmee Lee', \\ Jae Woong Choi ${ }^{1}$, Chang-Hee Lee ${ }^{1}$ \\ 1 Department of Radiology, Korea University Guro Hospital, Korea University College \\ of Medicine, Seoul; ' ${ }^{2}$ Department of Radiology, Korea University Ansan Hospital, Korea \\ University College of Medicine, Ansan; ${ }^{3}$ Department of Pathology, Korea University Guro \\ Hospital, Korea University College of Medicine, Seoul, Korea
}

Ultrasonography (US) is widely used for abdominal imaging. Its noninvasiveness, extensive range of application, and low cost make US a useful and valuable tool for the detection, diagnosis, and follow-up of splenic abnormalities. Concomitantly with the increasing frequency of imaging, more splenic lesions are being discovered and the requirements for the differential diagnosis are rising. In this pictorial essay, we introduce the representative US findings of many different splenic lesions, including normal sonographic findings, normal variants and congenital anomalies, infectious conditions, benign and malignant neoplasms, and non-neoplastic lesions. Knowledge of the US features of various splenic lesions will help narrow the differential diagnosis and guide clinical decision-making.

Keywords: Ultrasonography; Spleen; Splenic neoplasms; Splenic infarction; Splenic diseases Key points: Ultrasonography is a useful and valuable tool for the detection, diagnosis, and followup of splenic abnormalities.

\section{Introduction}

The spleen, sometimes called "the forgotten organ" of the abdomen, has received less attention than other abdominal solid organs, as splenic diseases are less common and frequently clinically asymptomatic [1]. However, with the increasing frequency of imaging and advances in imaging technology, more incidental splenic lesions are being discovered and the subsequent requirements for the differential diagnosis are growing.

Ultrasonography (US) is increasingly being used in clinical practice because of its strengths, which include accessibility, low cost, advances in imaging technology, and lack of radiation hazard. Therefore, US is widely used and frequently chosen as the first imaging modality for most abdominal imaging, both for general abdominal examinations and for patients suspected of having splenic diseases. However, to the authors' knowledge, there are not enough up-to-date ultrasonographic imaging reviews of splenic diseases [2-5]. Therefore, this pictorial essay elucidates the US findings of various splenic lesions, in correlation with computed tomography (CT) or magnetic resonance (MR) imaging and pathology.

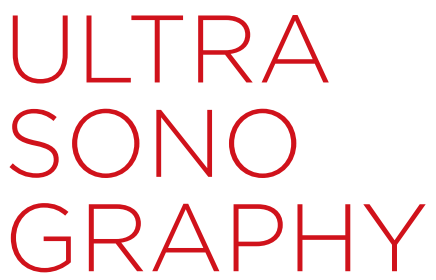

PICTORIAL ESSAY

https://doi.org/10.14366/usg.21189 pISSN: 2288-5919 e elSSN: 2288-5943 Ultrasonography 2022;41:416-429

Received: September 8, 2021

Revised: December 1, 2021

Accepted: December 2, 2021

Correspondence to: Kyeong Ah Kim, MD, PhD, Department of Radiology, Korea University Guro Hospital, Korea University College of Medicine, 148 Gurodong-ro, Guro-gu, Seoul 08308, Korea

Tel. +82-2-2626-1338

Fax. +82-2-863-9282

E-mail: kahkim@korea.ac.kr
This is an Open Access article distributed under the terms of the Creative Commons Attribution NonCommercial License (http://creativecommons.org/ licenses/by-nc/4.0/) which permits unrestricted noncommercial use, distribution, and reproduction in any medium, provided the original work is properly cited.

Copyright (C) 2022 Korean Society of Ultrasound in Medicine (KSUM)

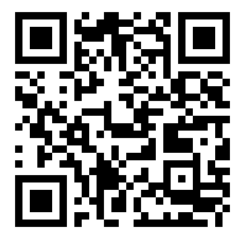

How to cite this article:

Choi G, Kim KA, Lee J, Park YS, Lee J, Choi JW, et al. Ultrasonographic atlas of splenic lesions. Ultrasonography. 2022 Apr;41(2):416-429. 


\section{Normal US of the Spleen}

The spleen is located in the left upper quadrant of the abdomen, posterolateral to the stomach. In US, the spleen is readily examined in several positions, including the supine, right lateral decubitus, and prone positions, through the subcostal or oblique intercostal plane, using a 3-5 MHz curved transducer [6].

The normal spleen shows a uniform echotexture similar to or slightly more hyperechoic than the liver or renal parenchyma. It has a crescent shape with a smooth outer convexity and a nodulous inner margin (Fig. 1) [3].

Generally, the upper limit of the normal spleen size is $11-12 \mathrm{~cm}$ in length and $7 \mathrm{~cm}$ in width, with splenomegaly defined as a length exceeding 11-12 cm in length; however, this threshold may vary based on the patient's age, sex, and body size [1,3].

\section{Normal Variants and Congenital Abnormalities of the Spleen}

\section{Accessory Spleen}

Accessory spleen, which results from a failure of the embryonic splenic anlage to fuse and extreme lobulation that separates splenic tissue, is a normal variant observed in $10 \%-30 \%$ of individuals [7]. It is usually found around the splenic hilum or ligaments, pancreatic tail, or sometimes in the pancreatic parenchyma [7]. US reveals a small $(1-3 \mathrm{~cm})$, separated, well-circumscribed, round to oval mass with echogenicity identical to that of the spleen (Fig. 2).

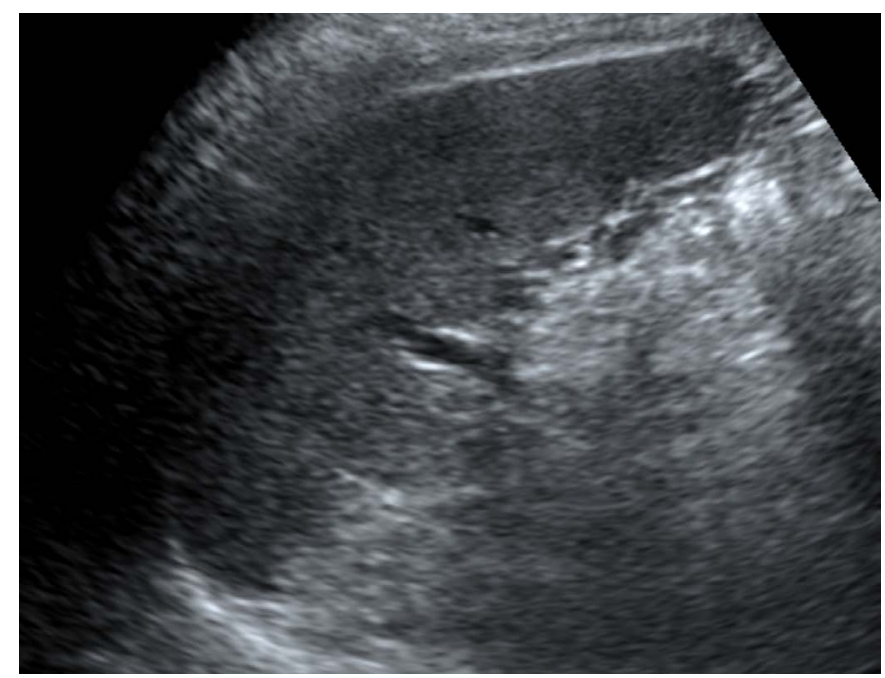

Fig. 1. A 49-year old man with a normal-appearing spleen on ultrasonography (US). Longitudinal US of the normal spleen shows homogeneous and uniform parenchymal echogenicity, and a crescent shape with smooth outer convexity and nodulous inner margin.
Intrapancreatic accessory spleen (IPAS) may mimic pancreatic neoplasms, but requires no further treatment. Therefore, a noninvasive imaging diagnosis is essential. The key US finding of IPAS is echogenicity identical to that of the spleen (Fig. 3). IPAS is usually surrounded by a high-amplitude interface representing a fibrotic capsule [8].

\section{Wandering Spleen}

Wandering spleen occurs when the spleen migrates from its normally fixed posterolateral location in the left upper abdomen. This

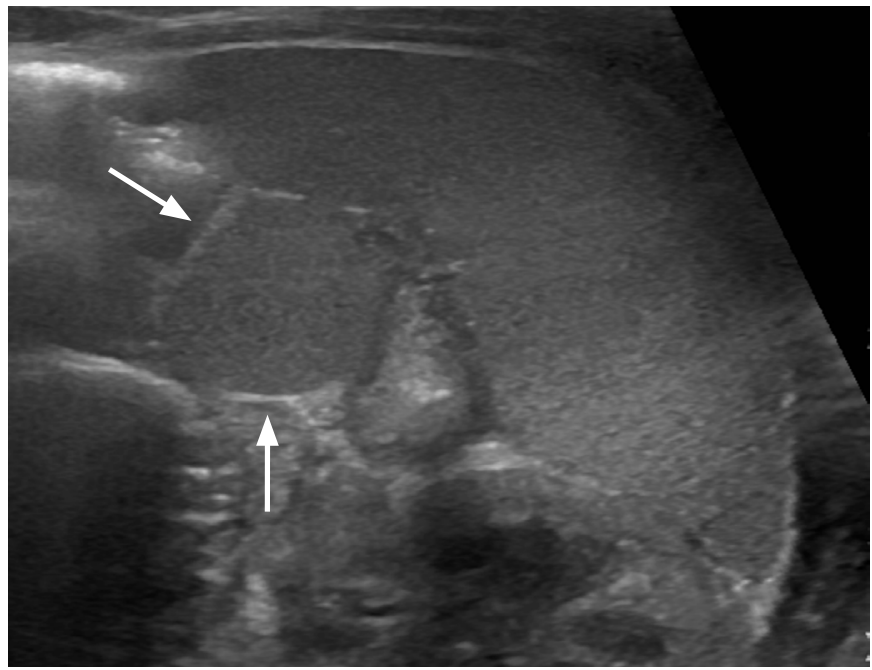

Fig. 2. A 3-year-old boy with an accessory spleen. Longitudinal ultrasonography of the spleen shows an approximately $1.2-\mathrm{cm}$ round to oval mass (arrows) with echogenicity identical to that of the spleen at the splenic hilum, suggesting an accessory spleen.

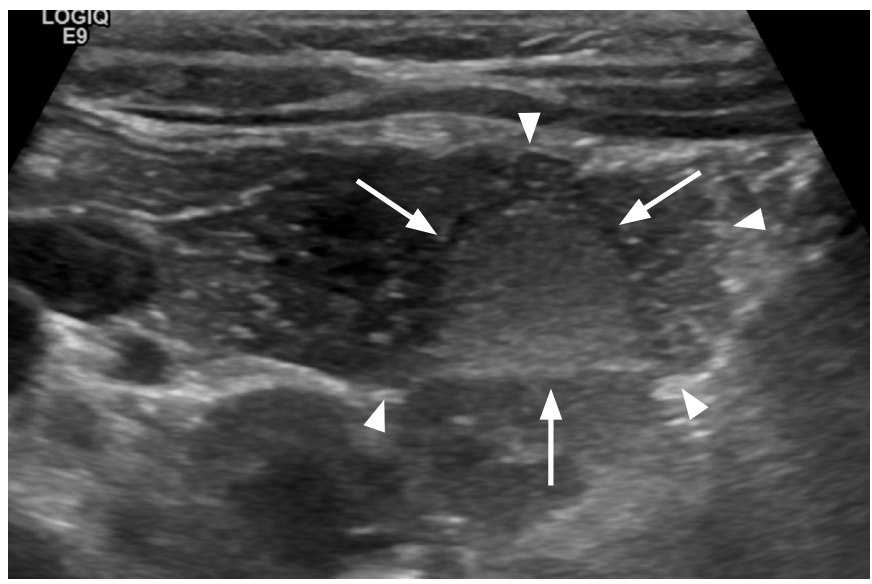

Fig. 3. A 6-year-old girl with an intrapancreatic accessory spleen (IPAS). Transverse ultrasonography of the pancreas shows a 1.3$\mathrm{cm}$ round to oval echogenic mass (arrows) in the pancreas tail (arrowheads), with echogenicity that is identical to that of the splenic parenchyma, suggesting IPAS. 
condition can be both congenital and acquired, and lacks normal anchoring by the gastrosplenic and splenorenal ligaments [7]. US is a valuable modality to diagnose wandering spleen located in ectopic sites and to evaluate complications, including torsion and infarction (Fig. 4). When complicated with torsion, an abnormally located hypoechoic spleen with a twisted vascular pedicle and decreased or absent perfusion on color Doppler US are characteristic findings [1]. In particular, real-time US is helpful for testing splenic hypermobility and vascular pedicle abnormalities [7].

\section{Infections and Splenic Abscesses}

\section{Bacterial Infections}

Splenic abscesses caused by bacterial infections mainly occur through hematogenous spread (75\%), penetrating trauma (15\%), and splenic infarction [9]. Pyogenic splenic abscesses appear as single or multiple poorly defined round to oval hypoechoic or anechoic cystic masses with variable posterior acoustic enhancement on US, according to the degree of necrosis, as well as an absence of internal vascularity on color Doppler US (Figs. 5,6) $[1,9]$. If the abscess contains internal air bubbles, hyperechoic foci with shadowing may be seen [4].

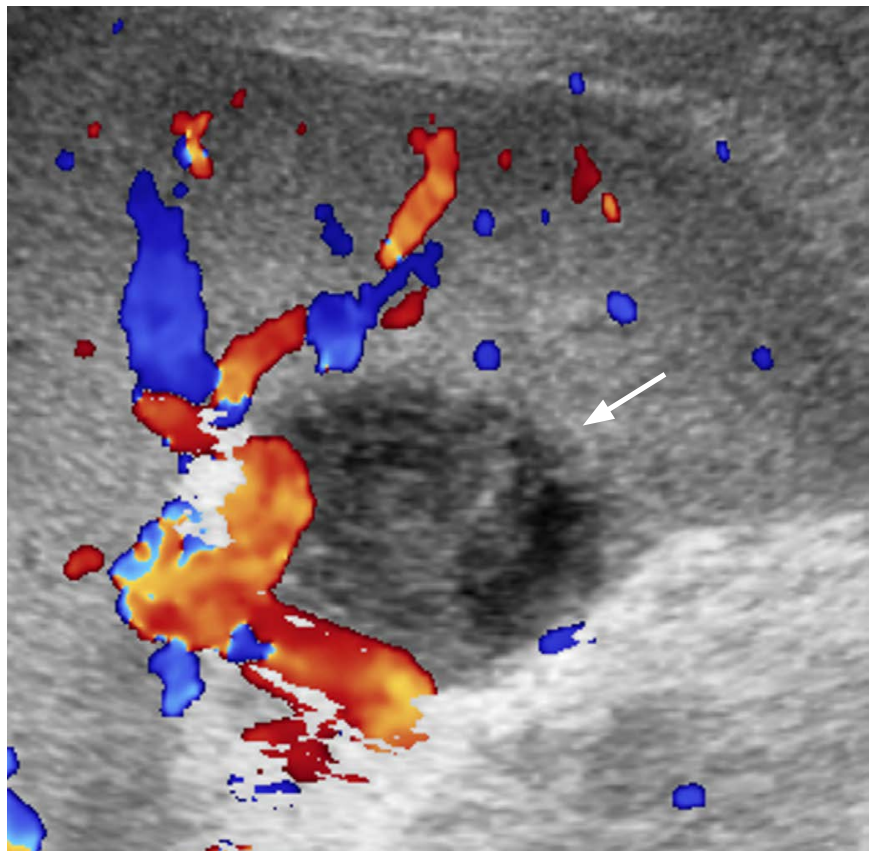

Fig. 5. A 60-year-old woman with pyogenic abscess of the spleen. Longitudinal ultrasonography (US) of the spleen shows an oval heterogeneous hypoechoic lesion (arrow) with mild acoustic enhancement in the splenic hilum suggesting an abscess. Klebsiella pneumoniae was identified in US-guided aspiration.

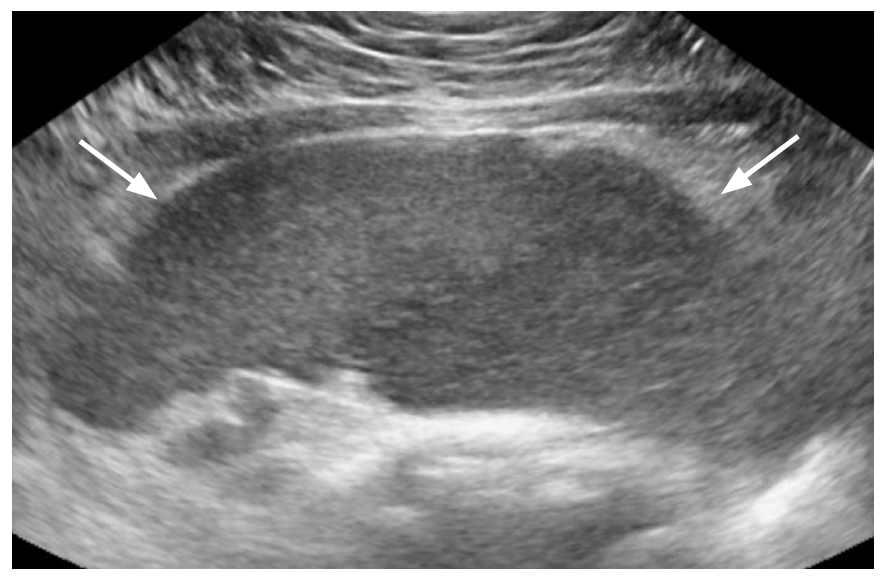

A

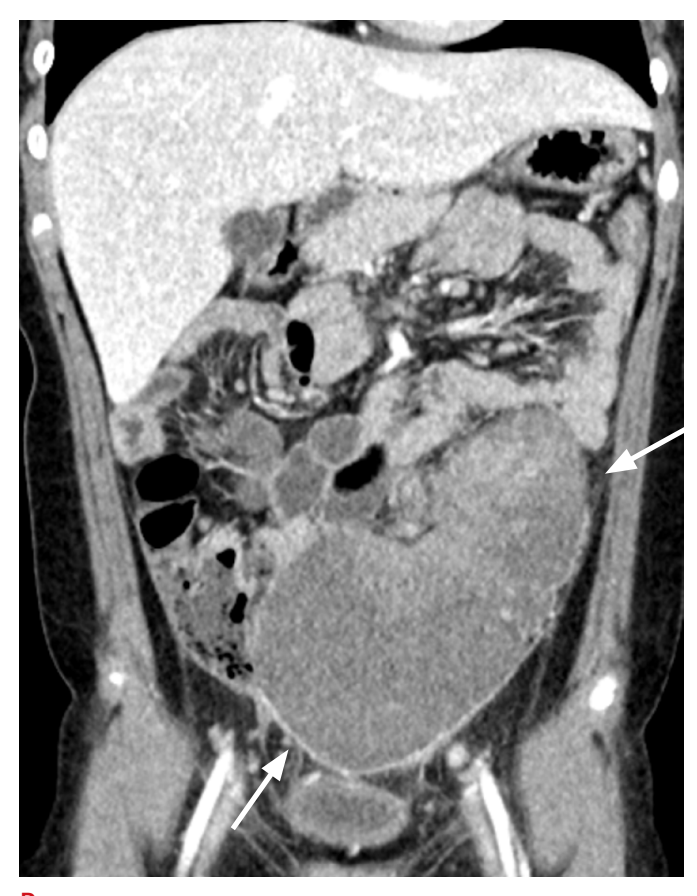

B

Fig. 4. An 8-year-old girl with a wandering spleen.

A. Transverse ultrasonography of the lower abdomen shows a crescent-shaped homogeneous abdominal mass (arrows) suggesting that the spleen is in an unusual anatomical location, a condition known as "wandering spleen." In this patient, the ectopic spleen was enlarged and the parenchymal echogenicity was heterogeneous. B. Follow-up computed tomography scan of the same patient with abdominal pain shows torsion and ischemia of the wandering spleen (arrows). 


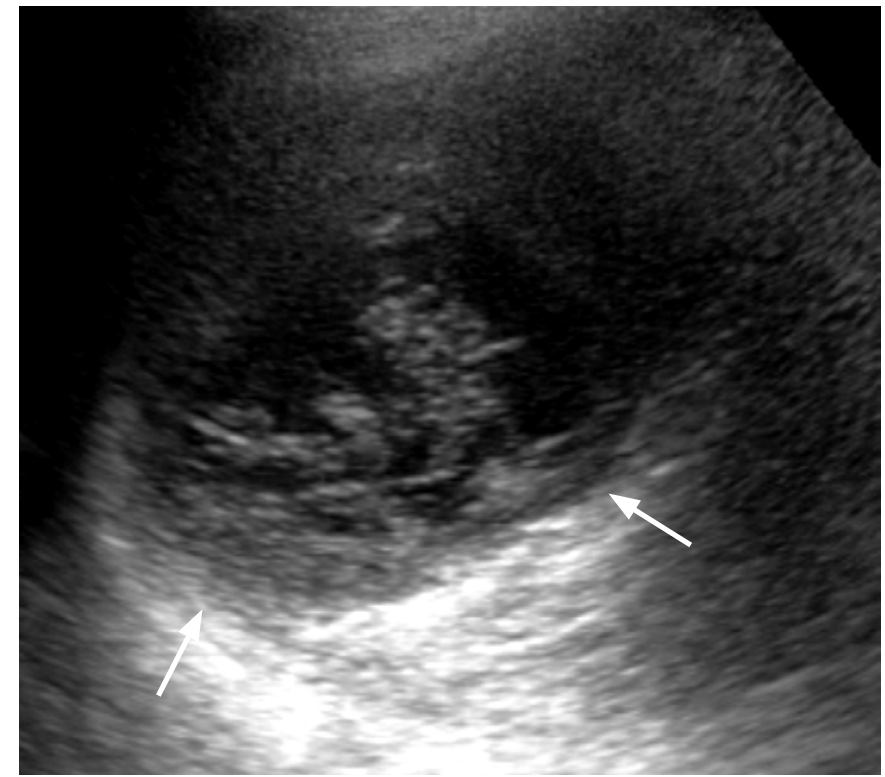

A

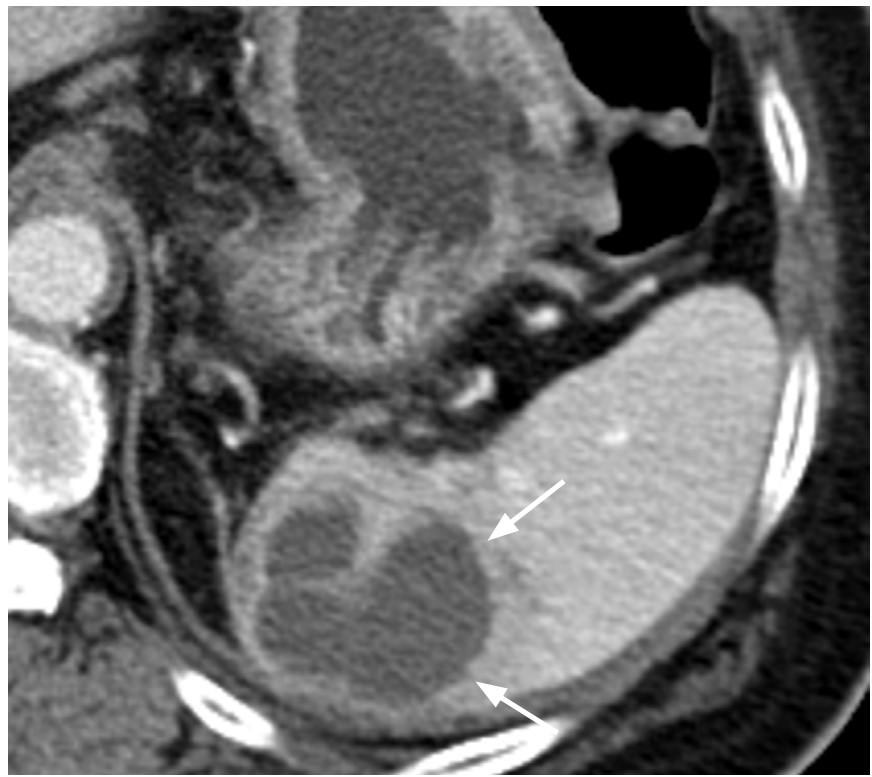

B

Fig. 6. A 65-year-old woman with pyogenic abscess of the spleen.

A. Longitudinal ultrasonography (US) of the spleen shows a poorly defined round anechoic cystic mass (arrows) with echogenic internal debris suggestive of an abscess. Salmonella group D was identified by US-guided aspiration. B. Axial contrast-enhanced computed tomography image shows a rim-enhancing multiseptated hypodense lesion (arrows) in the spleen.

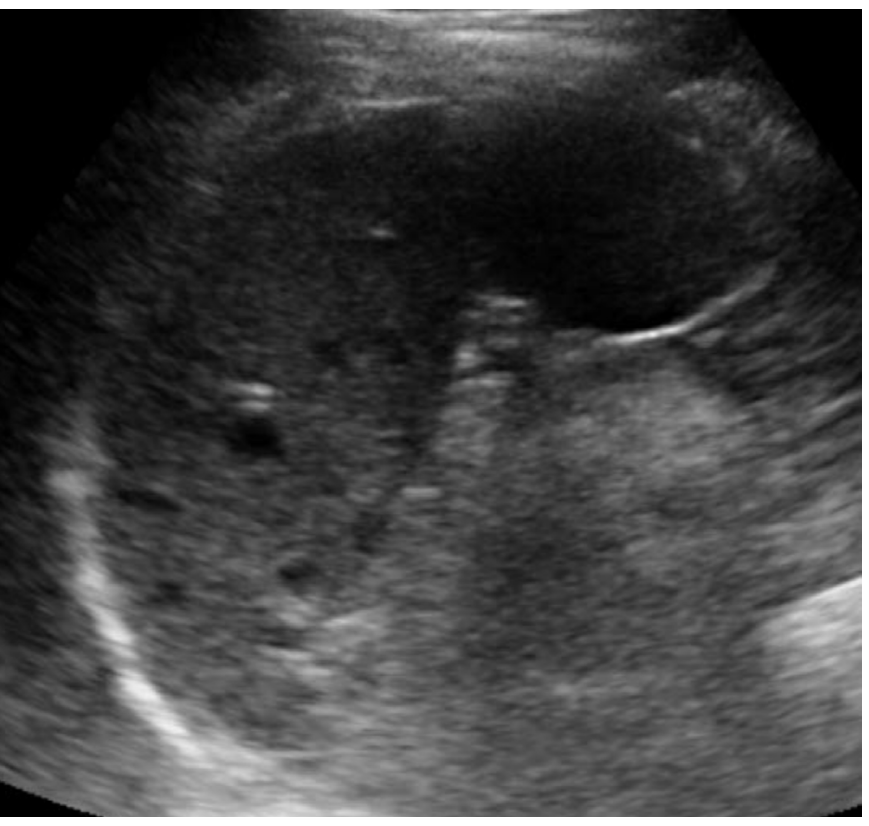

A

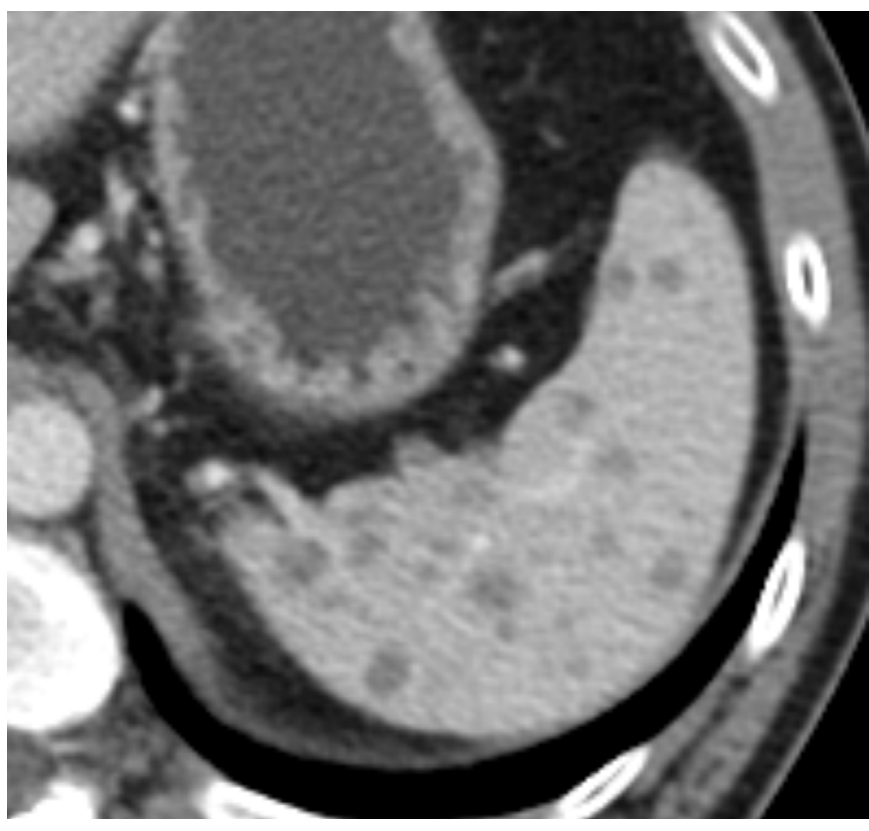

B

Fig. 7. A 35-year-old human immunodeficiency virus-positive man with miliary tuberculosis infection of the spleen.

A. Longitudinal ultrasonography (US) of the spleen shows multiple small $(<1 \mathrm{~cm})$ hypoechoic lesions in the splenic parenchyma. US-guided biopsy confirmed the presence of Mycobacterium tuberculosis. B. Axial contrast enhanced computed tomography image shows numerous, subcentimeter, hypodense nodular lesions throughout the spleen. 


\section{Fungal Infections}

Fungal splenic abscesses typically occur in immunocompromised patients with neutropenia, most commonly by Candida, Aspergillus, and Cryptococcus. Fungal lesions appear as hypoechoic multiple micro-abscesses (mostly 5-10 mm and almost always $<20 \mathrm{~mm}$ ) $[1,10]$. Characteristically, Candida infections show "bulls-eye" or "wheel within a wheel" patterns, consisting of different layers of necrosis, inflammation, and fibrosis [1].

\section{Splenic Tuberculosis}

Mycobacterial splenic involvement can develop in disseminated miliary tuberculosis (TB) infections $[1,10]$. The US findings include multiple hypoechoic nodules, abscesses, and splenomegaly (Fig. 7) [1]. Additional findings such as enlarged and conglomerated lymph nodes, bowel wall thickening, and ascites seen in abdominal TB may

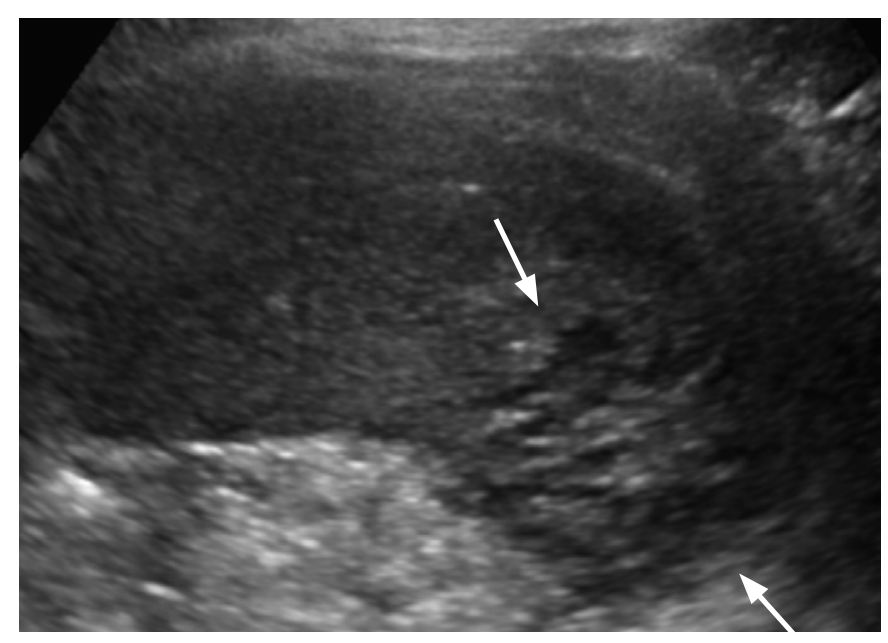

A

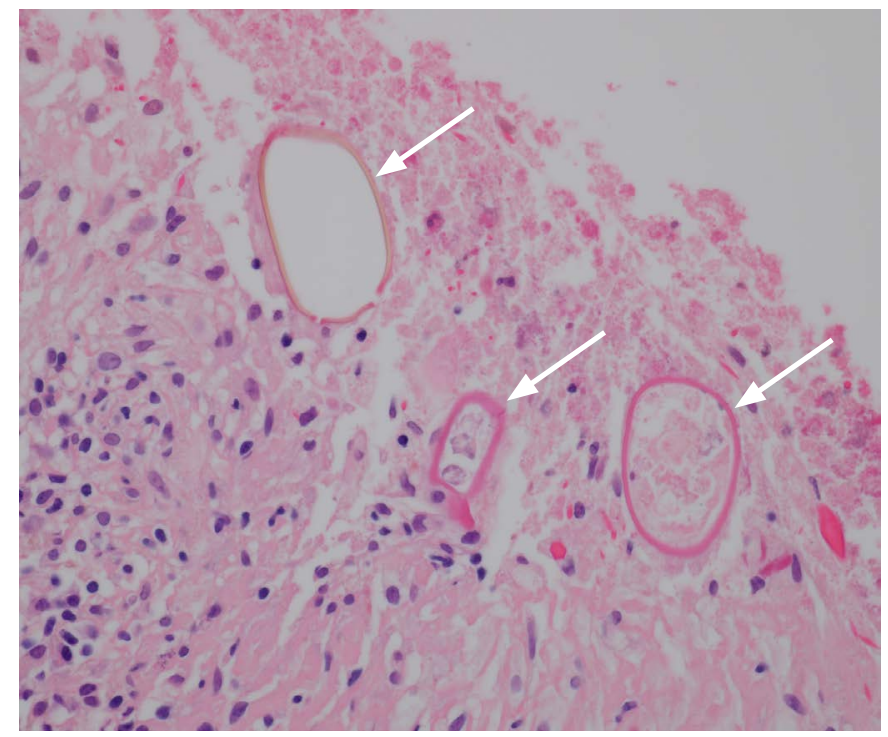

be helpful [1]

\section{Parasitic Infections and Infestations}

Most parasitic splenic lesions are hydatid cysts caused by Echinococcus granulosus. The US findings depend on the stage of the cyst and its associated complications. Anechoic fluid-filled cysts with various internal echogenic materials representing intracystic debris, hydatid sand, inflammation, or pathognomonic findings such as the "water lily" sign of collapsed floating membranes, as well as multiple small peripheral daughter cysts, may be observed [1,2]. In addition, splenic paragonimiasis has been reported in endemic areas; this condition appears as a splenic mass composed of clusters of small anechoic cysts (Fig. 8) [11].

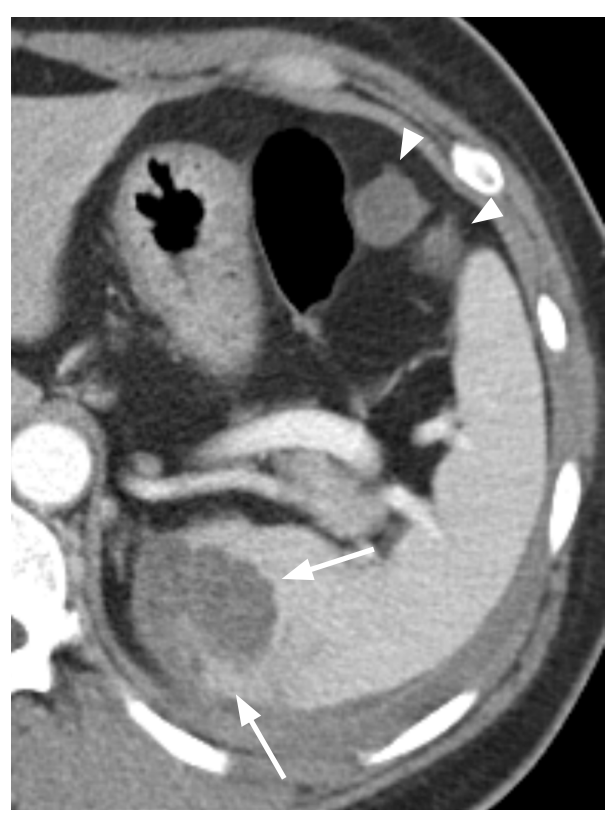

B

Fig. 8. A 44-year-old woman with paragonimiasis.

A. Longitudinal ultrasonography (US) of the spleen shows an approximately $3.5-\mathrm{cm}$ clustered multicystic lesion (arrows). USguided biopsy confirmed eggs from Paragonimus westermani. B. Axial contrast-enhanced computed tomography image shows a lobulated hypodense splenic lesion with clustered multiple cysts (arrows). Two small peritoneal cystic lesions (arrowheads) and left pleural effusion were also observed. C. Microscopic image with hematoxylin and eosin staining $(\times 400)$ shows the ovoid parasite eggs with a thick shell (arrows) in necrotic splenic tissue, morphologically consistent with $P$. westermani. 


\section{Benign Neoplasms}

\section{Hemangioma}

Hemangioma is the most common benign neoplasm of the spleen; it is mostly asymptomatic and is usually found incidentally $[1,12]$. Smaller splenic hemangiomas, which are more common, appear as discrete echogenic lesions (Fig. 9) similar to those in the liver. Larger hemangiomas occasionally cause symptoms such as abdominal pain, a palpable mass, spontaneous bleeding when ruptured, or
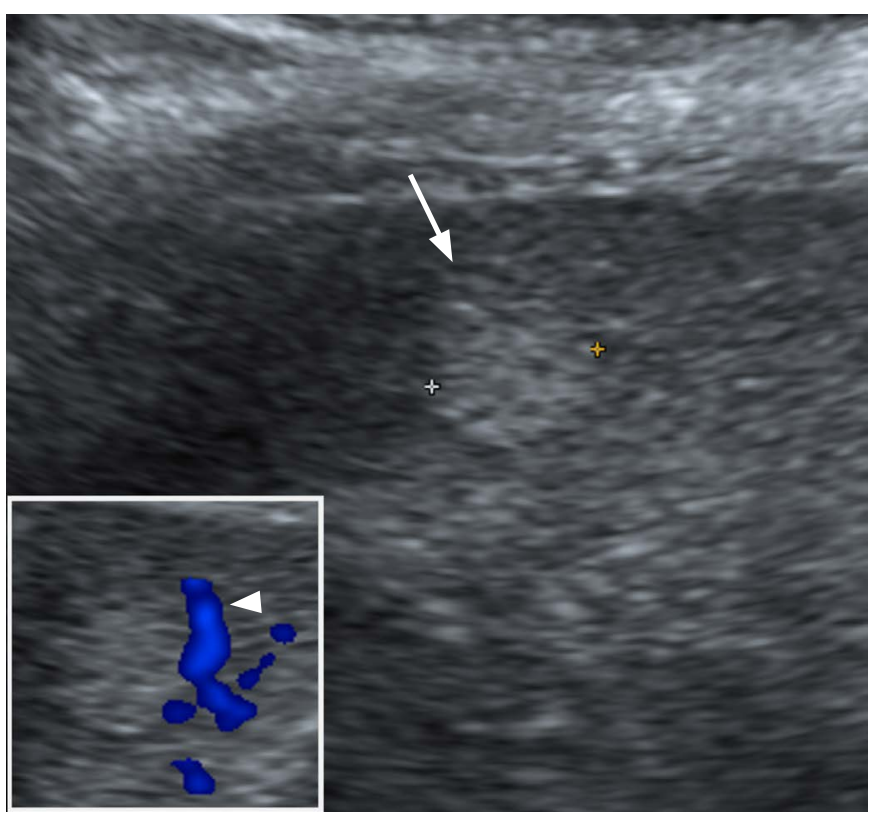

\section{A}

Kasabach-Merritt syndrome, which involves the triad of anemia, thrombocytopenia, and coagulopathy. Larger ones may appear as complex solid and cystic masses (Fig. 10) due to infarction, thrombosis, hemorrhage, or fibrosis, and with acoustic shadowing due to calcifications $[1,2,12]$. On color Doppler US, there may be intralesional or peripheral vascularity or no flow [5].

\section{Hamartoma}

Splenic hamartoma is a rare benign tumor, known as "a spleen

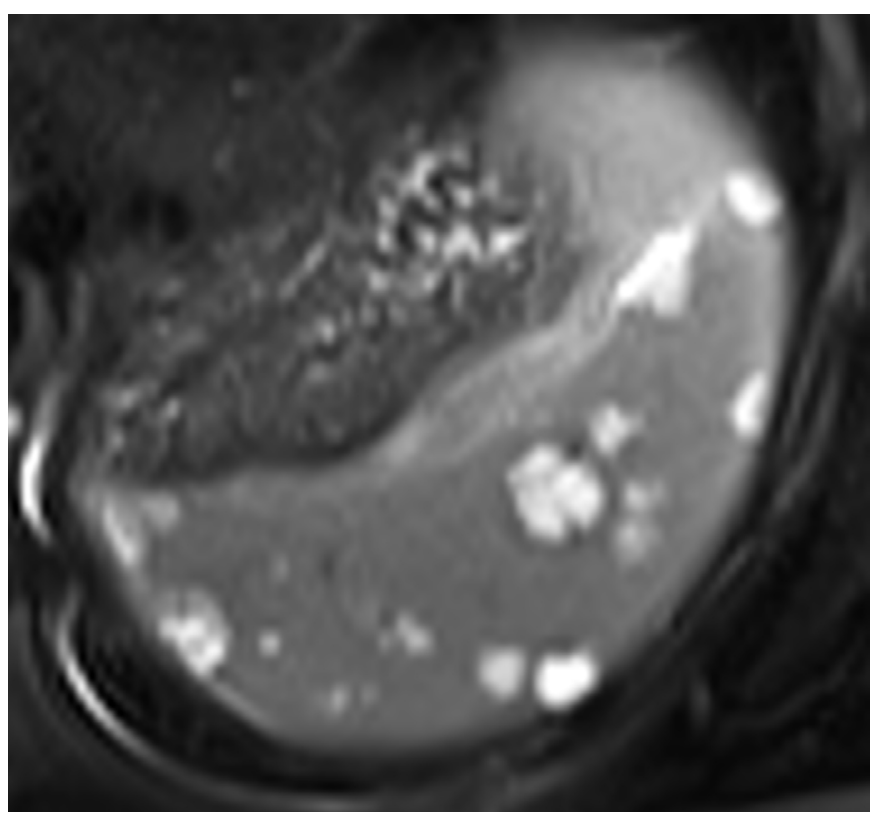

B

Fig. 9. A 33-year-old woman with a splenic hemangioma.

A. Longitudinal ultrasonography (US) of the spleen shows an incidentally found, discrete, round, echogenic nodule (arrow). Color Doppler US (box) showed peripheral vascularity (arrowhead) of the nodule. B. Axial magnetic resonance imaging; a T2-weighted image shows multiple well-defined, round, $\mathrm{T} 2$ high-signal-intensity lesions suggestive of hemangiomas.

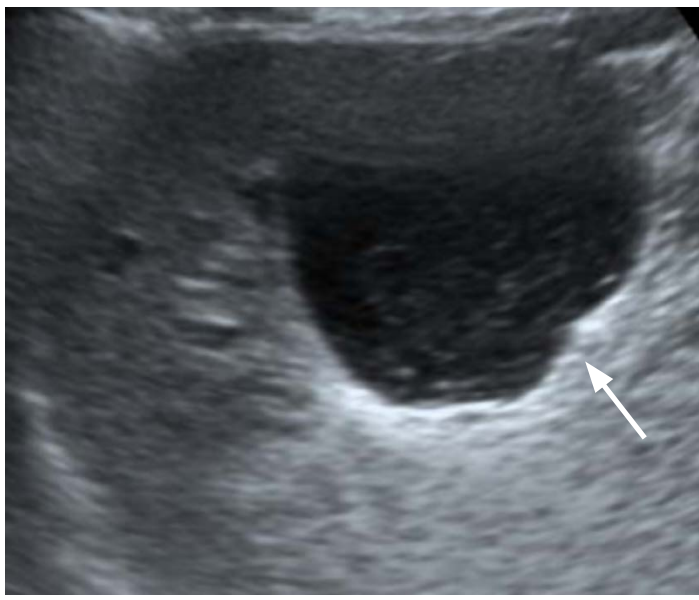

A

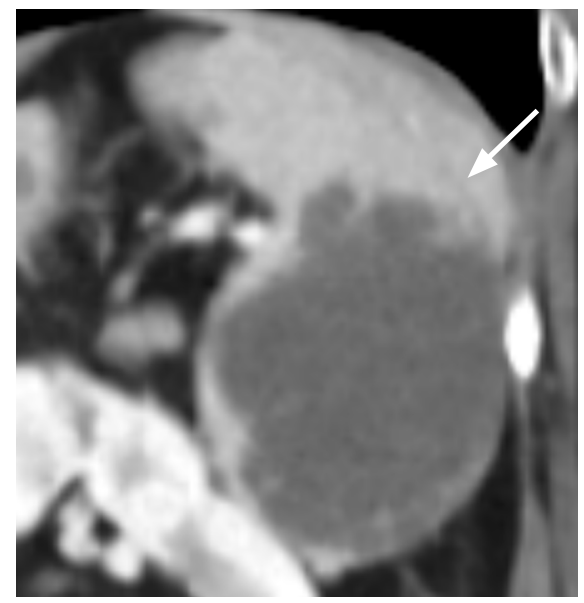

B
Fig. 10. A 61-year-old woman with a splenic hemangioma. A. Longitudinal ultrasonography of the spleen shows a lobulated cystic lesion (arrow) at the splenic inferior pole with an internal echogenic solid portion. B. Coronal contrast-enhanced computed tomography image shows a lobulated low-density lesion (arrow) in the splenic inferior pole. 
within a spleen," composed of malformed normal splenic tissue caused by post-traumatic scar, nodular hyperplasia, or hyperplastic nodules. It typically appears as a single well-defined homogeneous isoechoic to hyperechoic nodule or mass on US (Fig. 11) [1,12]. The characteristic hypervascularity of the hamartoma's red pulp is reflected as a hypervascular pattern on color Doppler US [12].

\section{Lymphangioma}

Lymphangioma is a benign slow-growing congenital neoplasm, typically seen in childhood. US is advantageous for evaluating the contents and shape of the cystic lesions, in which splenic lymphangioma appears as a well-defined thin-walled multilocular cystic lesion located in the subcapsular area of the spleen, and may contain intralocular echogenic debris, hyperechoic septations, and thin mural calcifications (Fig. 12) [5]. In addition, vascularity along the walls of the cysts in color Doppler US is helpful for the diagnosis [1].

\section{Sclerosing Angiomatoid Nodular Transformation}

Sclerosing angiomatoid nodular transformation (SANT) is a rare benign non-neoplastic vascular lesion composed of multiple angiomatoid nodules interspersed with fibrous bands [13]. Most cases are asymptomatic and found incidentally. On US, SANT appears as a solitary round heterogeneous (usually hypoechoic) mass, sometimes with visible linear hyperechoic septae, and arterial flow signals on color Doppler US (Fig. 13A) [14]. Contrast-enhanced US, CT, and MR imaging show a well-circumscribed solitary mass with peripheral enhancing radiating lines, referred to as a "spoke wheel" appearance (Fig. 13B) [13].

\section{Malignant Neoplasms}

\section{Lymphoma}

Lymphoma is the most common malignancy of the spleen $[2,15]$.

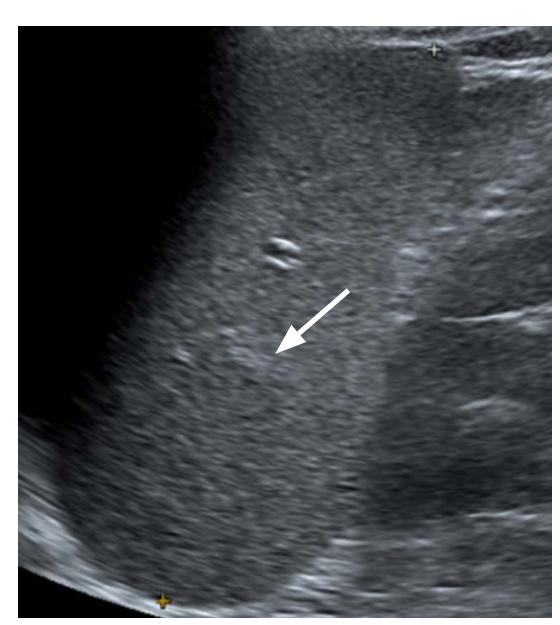

A

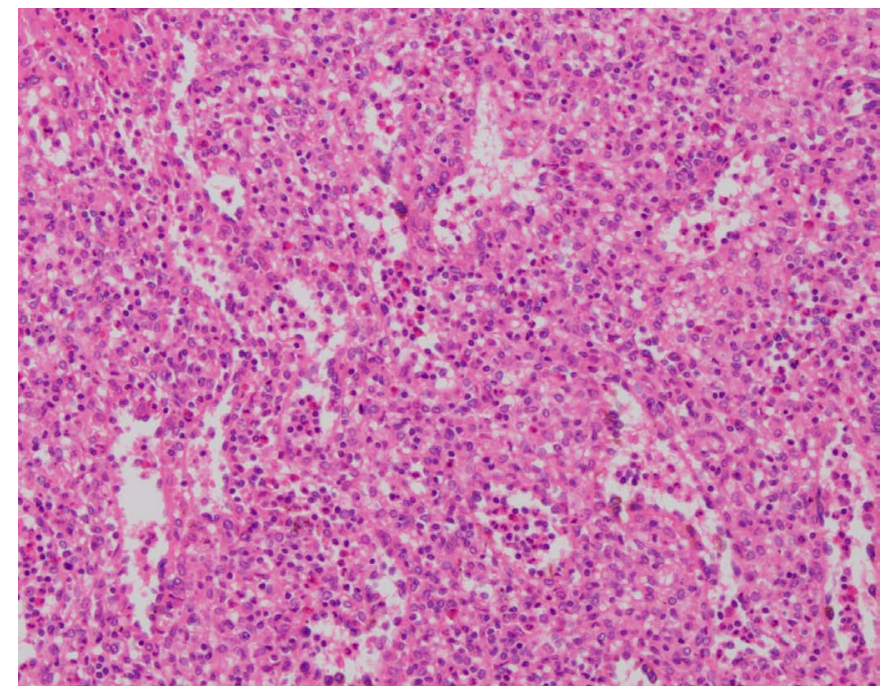

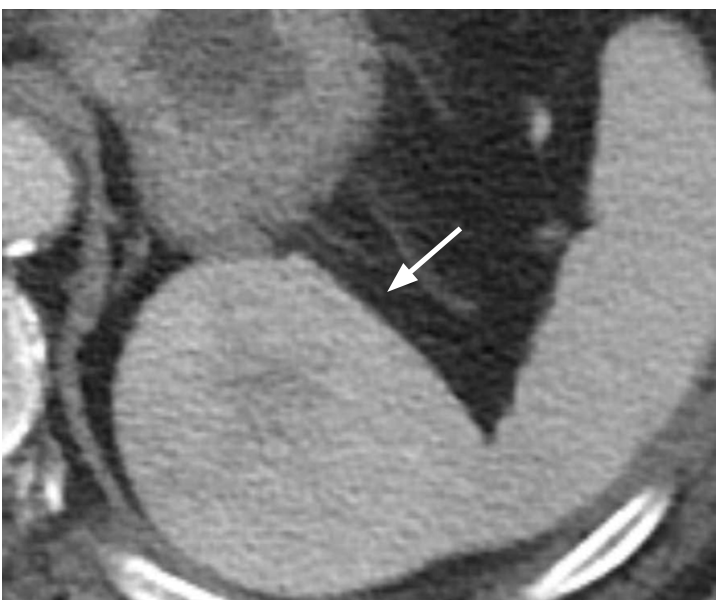

B
Fig. 11. A 70-year-old man with a splenic hamartoma.

A. Longitudinal ultrasonography of the spleen shows an approximately $5-\mathrm{cm}$, homogeneously isoechoic round mass (arrow) in the splenic upper pole. B. Axial contrast-enhanced computed tomography image shows a heterogeneously enhancing round mass (arrow) in the spleen, which was confirmed to be a hamartoma. C. Microscopic image with hematoxylin and eosin stain $(\times 100)$ shows disorganized blood vessels of varying sizes intermingled with splenic red pulp. 


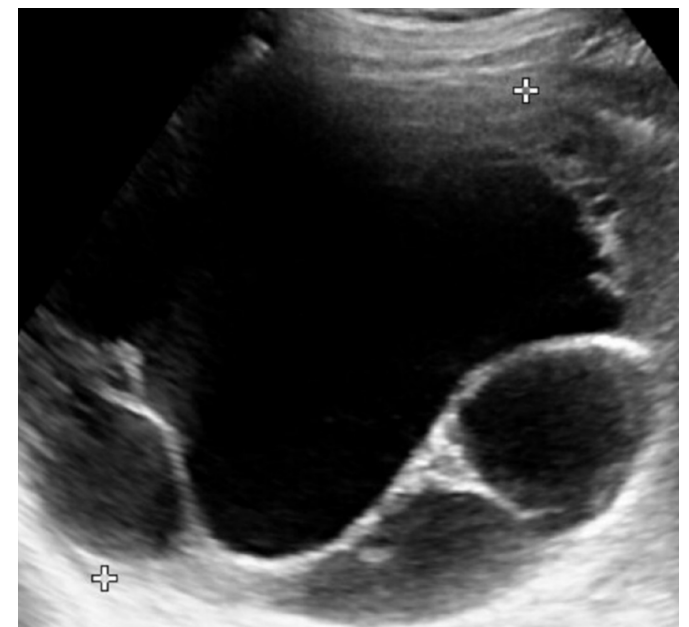

A

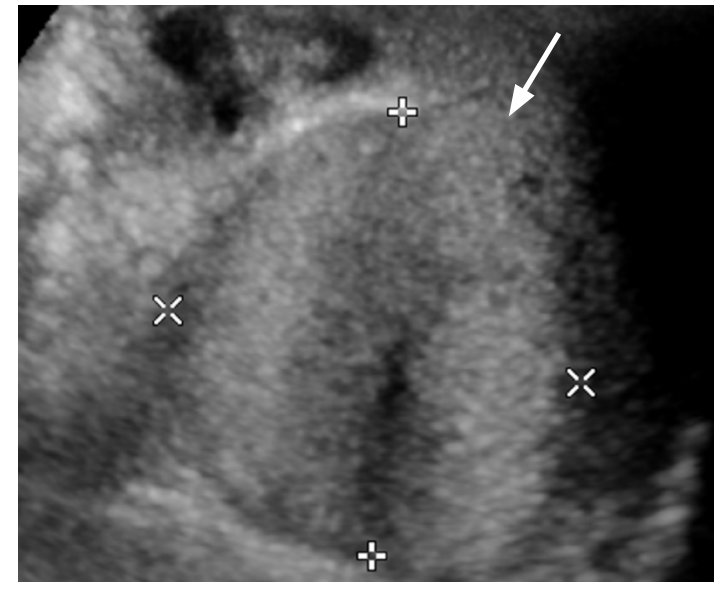

A

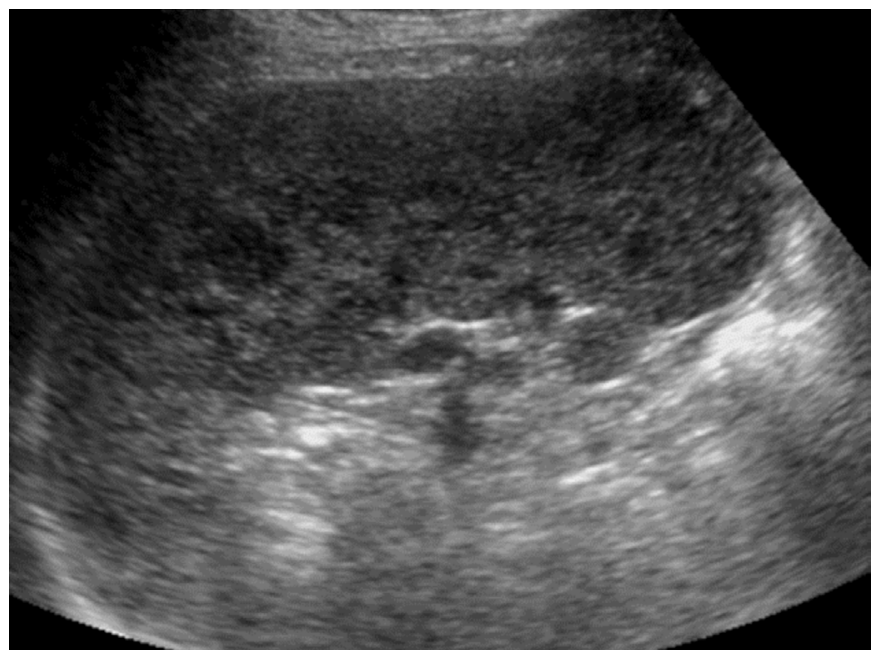

A

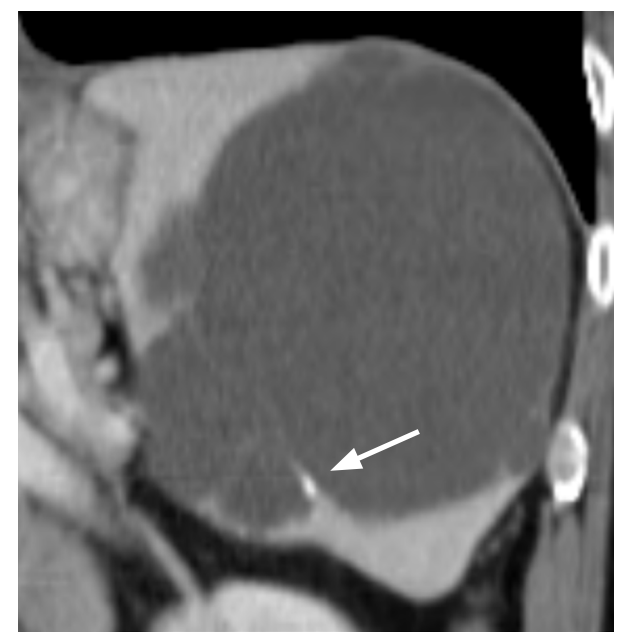

B

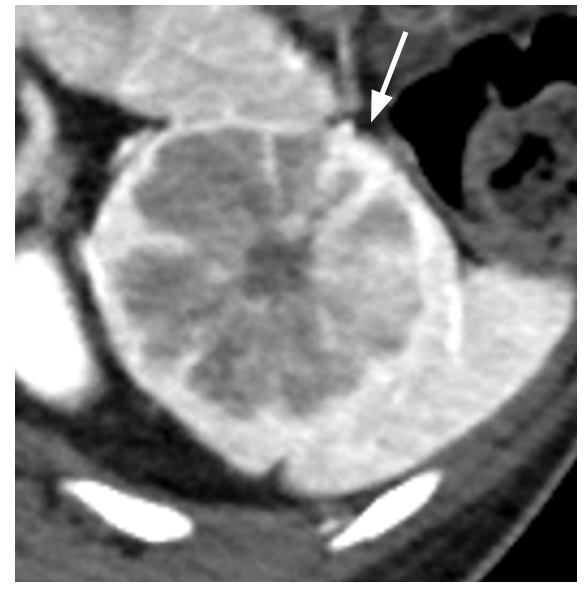

B
Fig. 12. A 74-year-old woman with splenic lymphangioma. A. Transverse ultrasonography of the spleen shows an incidentally observed multiloculated cystic lesion measuring approximately $12 \mathrm{~cm}$ in the splenic upper pole. B. Coronal contrast-enhanced computed tomography image shows a multiloculated large cystic lesion with thin-wall calcification (arrow).

Fig. 13. A 51-year-old woman with splenic sclerosing angiomatoid nodular transformation (SANT).

A. Longitudinal ultrasonography of the spleen shows an approximately $5 \mathrm{~cm} \times 4 \mathrm{~cm}$ well-defined oval echogenic mass (arrow). B. Axial image of contrast-enhanced computed tomography shows the characteristic "spoke wheel" appearance (arrow) suggesting SANT.

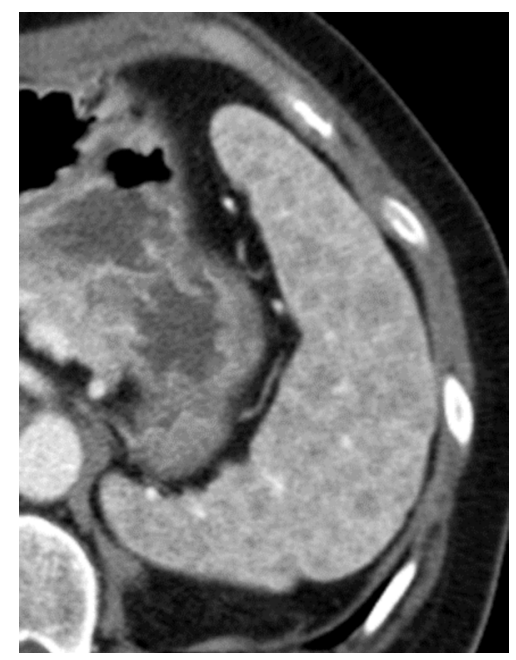

B

Fig. 14. A 56-year-old woman with diffuse large B-cell lymphoma (DLBCL).

A. Longitudinal ultrasonography (US) of the spleen shows numerous conglomerated hypoechoic nodules. B. Axial contrast-enhanced computed tomography image shows numerous hypodense nodules in the spleen. US-guided biopsy confirmed DLBCL involvement of the spleen. 
Secondary involvement is much more common, in that $30 \%-$ $40 \%$ of lymphoma patients show splenic involvement, while primary lymphoma of the spleen is rare $(<1 \%)$ [16]. The various patterns include diffuse infiltration causing alterations in the splenic echotexture and enlargement, miliary nodules, multiple solid nodules or masses (Fig. 14), and a large solitary mass (Fig. 15). The lesions are generally hypoechoic compared to normal splenic parenchyma and avascular on color Doppler US [1-3,15].

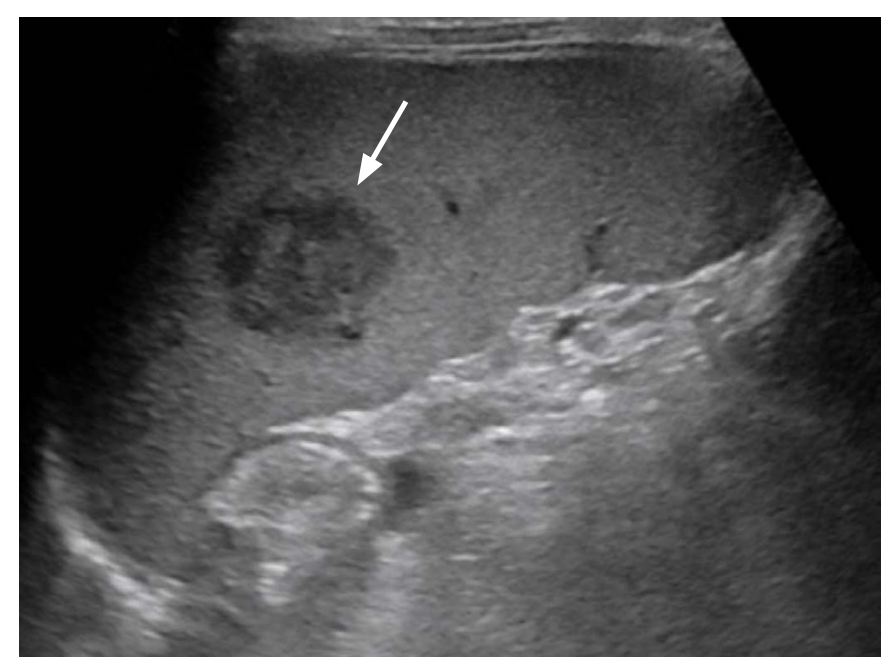

Fig. 15. A 6-year-old boy with systemic Epstein-Barr virus-positive T-cell lymphoma of childhood. Longitudinal ultrasonography of the spleen shows a heterogeneously hypoechoic mass (arrow) with splenomegaly $(11.5 \mathrm{~cm})$.

\section{Metastases}

Splenic metastasis is uncommon except for lymphoma, and is usually seen in advanced stages of various malignancies. The frequent primary malignancies of splenic metastases are melanoma and cancers of the breast, ovary, colon, lung, and prostate. Most metastases occur as solitary or multiple nodules. While approximately $50 \%$ are hypoechoic, this varies according to the primary tumor, and hyperechoic (especially from melanoma and colon cancer) (Fig. 16), mixed echoic, cystic, and target appearances are also possible $[1,2,15]$. Most metastatic nodules or masses are avascular on color Doppler US [17].

\section{Angiosarcoma}

Angiosarcoma is the most common primary nonhematopoietic malignant neoplasm of the spleen. It is highly malignant and develops from the endothelial lining of blood vessels in spleen. On US, it is seen as well-defined heterogeneous solitary or multiple nodules or masses with hemorrhagic or necrotic changes, or splenomegaly in diffusely infiltrative cases [1,2]. In color Doppler US, increased blood flow may be seen in the hyperechoic solid portion $[5,12]$.

\section{Non-neoplastic Lesions}

\section{Splenomegaly}

Splenomegaly can be diagnosed in patients with acute or chronic splenic enlargement, with splenic length $>11-12 \mathrm{~cm}$ and width

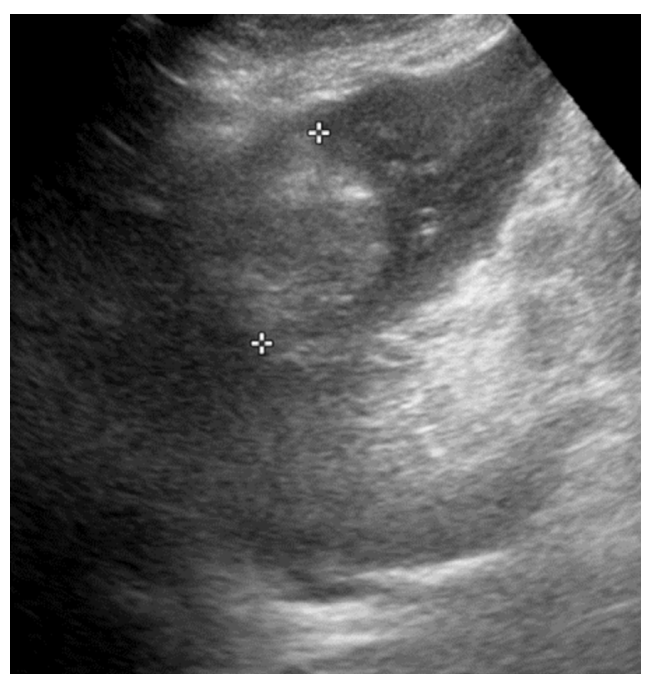

A

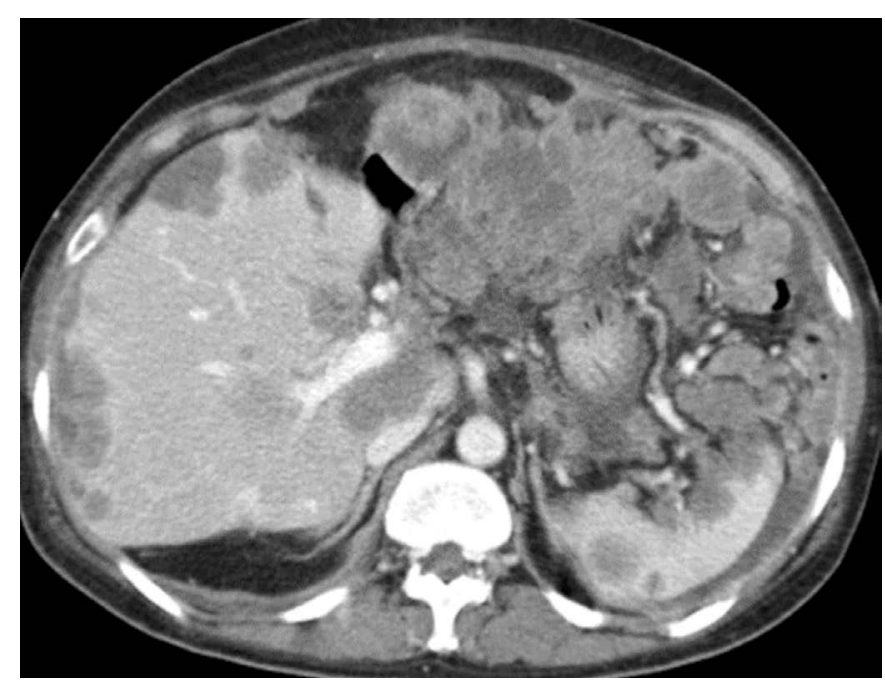

B

Fig. 16. A 48-year-old woman with rectal cancer with multiple metastases including splenic metastasis and peritoneal carcinomatosis. A. Longitudinal ultrasonography of the spleen shows a round echogenic mass suggestive of metastasis. B. Axial contrast-enhanced computed tomography image shows multiple metastases to the liver, spleen, lymph nodes, and peritoneal carcinomatosis. 
$>7 \mathrm{~cm}$ (Fig. 17) [1,3]. Various conditions cause diffuse enlargement of the spleen, including congestive, hyperplastic, inflammatory, infectious, and infiltrative causes (Table 1). US alone cannot determine the exact cause of splenomegaly, but it is necessary to confirm and quantify splenomegaly, and ancillary findings on US examinations may be helpful for patient evaluation [1].

\section{Splenic Cysts}

Congenital or epidermoid splenic cysts are developmental cystic lesions with an epithelial lining [18]. In US, epidermoid cysts appear as well-defined unilocular anechoic lesions with a thin wall, sometimes with septations and wall calcifications (Fig. 18) [1].

Secondary cysts or pseudocysts differ from congenital cysts in that they lack an epithelial lining and mostly develop secondarily from previous trauma, infarction, or infection [16]. The US findings of secondary cysts are similar to those of congenital cysts, to the point

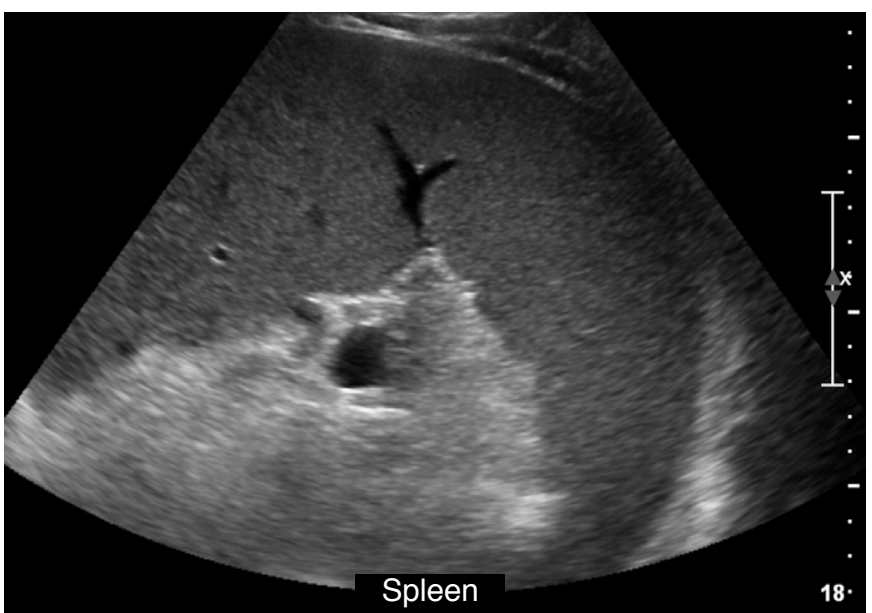

A

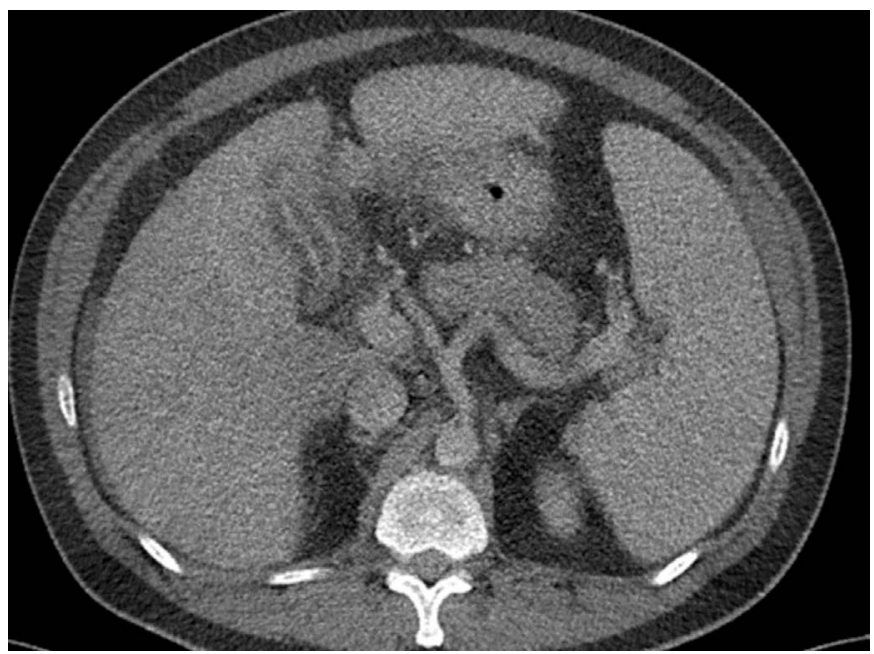

C

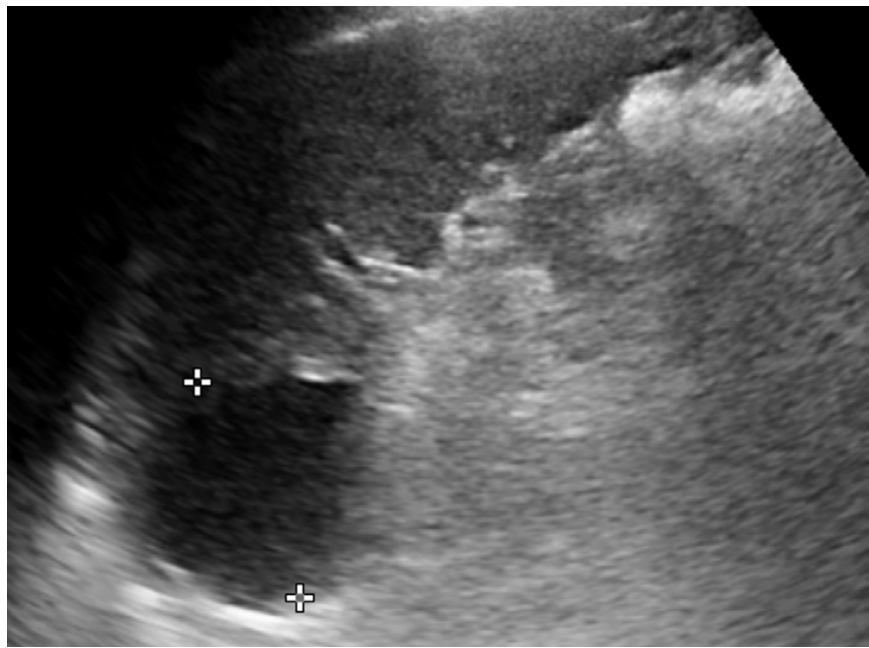

Fig. 18. An 83-year-old man with a splenic cyst. Longitudinal ultrasonography of the spleen shows an approximately $4-\mathrm{cm}$ welldefined round anechoic cystic lesion at the splenic upper pole.

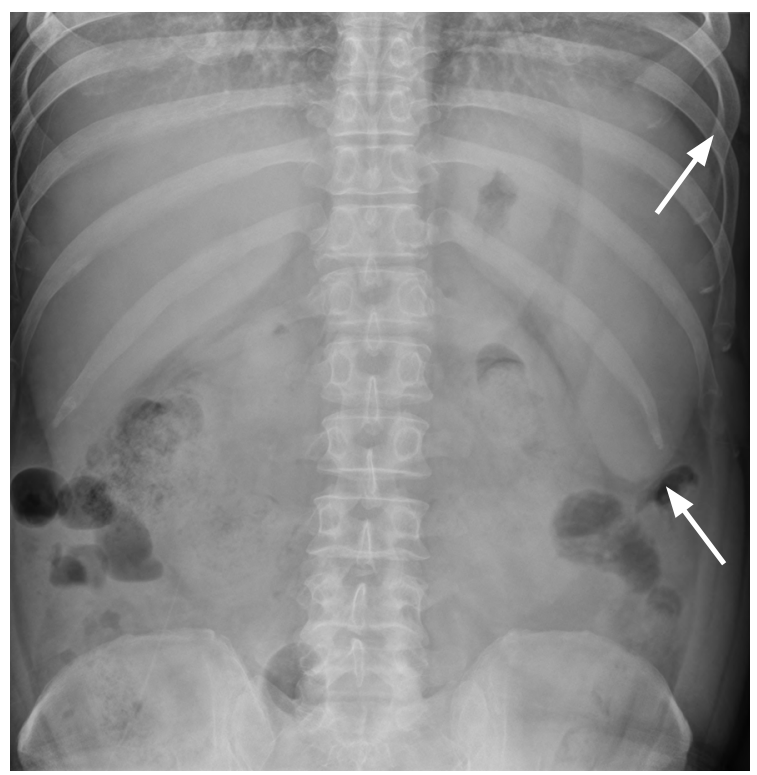

B

Fig. 17. A 33-year-old man with splenomegaly and alcoholic hepatitis.

A-C. Longitudinal ultrasonography of the spleen $(A)$, abdominal plain radiograph $(B)$, and axial abdominal computed tomography image (C) shows splenomegaly $(>21 \mathrm{~cm}$ in length, arrows in $B$ indicate enlarged splenic shadow). 
that they cannot be reliably distinguished; however, secondary cysts with hemorrhage or infection may show internal debris and thicker walls $[1,4]$.

\section{Splenic Infarction}

The splenic artery is a terminal artery; therefore, occlusion of its

Table 1. Various conditions causing splenomegaly

\begin{tabular}{|c|c|}
\hline Congestive & $\begin{array}{l}\text { Liver cirrhosis, portal hypertension } \\
\text { Portal/Splenic vein thrombosis } \\
\text { Congestive heart failure }\end{array}$ \\
\hline Infectious & $\begin{array}{l}\text { Acute infections (e.g., infectious mononucleosis, } \\
\text { endocarditis) } \\
\text { Chronic infections (e.g., miliary tuberculosis, malaria, } \\
\text { AIDS) }\end{array}$ \\
\hline Inflammatory & $\begin{array}{l}\text { Sarcoidosis } \\
\text { Systemic lupus erythematosus }\end{array}$ \\
\hline Neoplastic & $\begin{array}{l}\text { Lymphomas, leukemias } \\
\text { Metastases }\end{array}$ \\
\hline Infiltrative & $\begin{array}{l}\text { Myeloproliferative disorders, extramedullary } \\
\text { hematopoiesis } \\
\text { Storage diseases (e.g., Gaucher's disease, amyloidosis, } \\
\text { mucopolysaccharidoses) }\end{array}$ \\
\hline
\end{tabular}

AIDS, acquired immune deficiency syndrome. branches causes splenic infarction $[1,18]$. Underlying hemolytic anemia (such as sickle cell disease), hematological malignancy, vasculitis, cardiac emboli, portal hypertension, and infiltrative disorders are known predisposing conditions $[5,19]$. US changes can be seen at least 24 hours after infarction, as a wedge-shaped hypoechoic area and lack of a color Doppler signal (Fig. 19) [1]. In addition, an infarction may show a mass-like appearance with irregular margins, or a multinodular or mottled appearance. In the chronic stage, the area of splenic infarction shrinks, and the echogenicity increases with fibrosis.

\section{Gamna-Gandy Bodies}

Gamna-Gandy bodies are siderotic nodules resulting from focal organized hemorrhagic infarcts [6], which can occur in patients with congestive splenomegaly, sickle cell disease, hemolytic anemia, leukemia, lymphoma, acquired hemochromatosis, and multiple blood transfusions [20]. On US, they typically appear as multiple punctate hyperechoic foci scattered in the spleen (Fig. 20) [6].

\section{Peliosis}

Splenic peliosis is a rare pathology characterized by sinusoidal dilatation and the formation of multiple cyst-like, blood-filled cavities

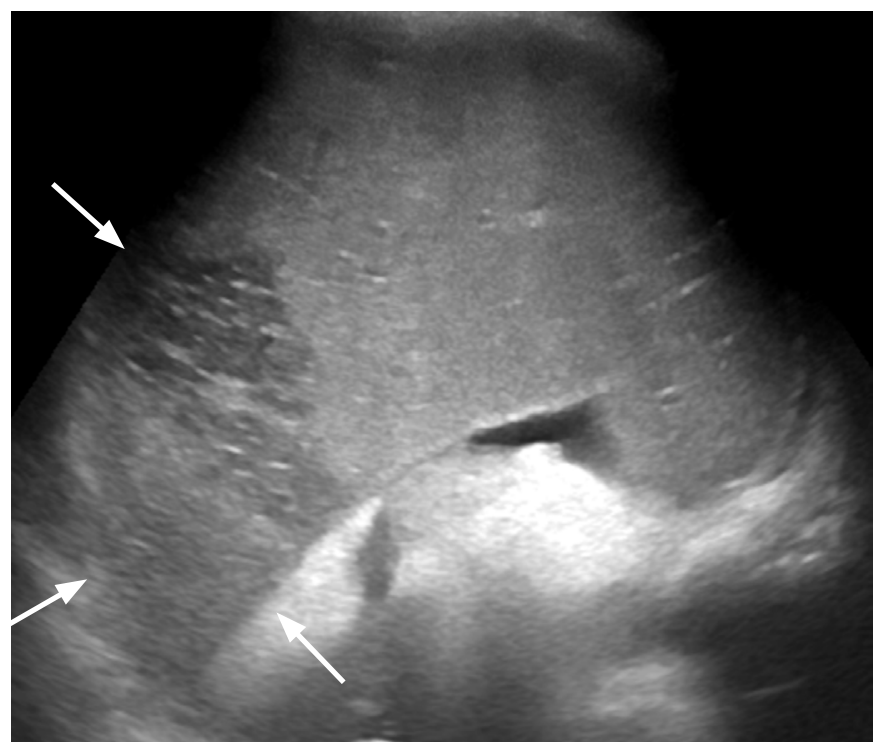

A

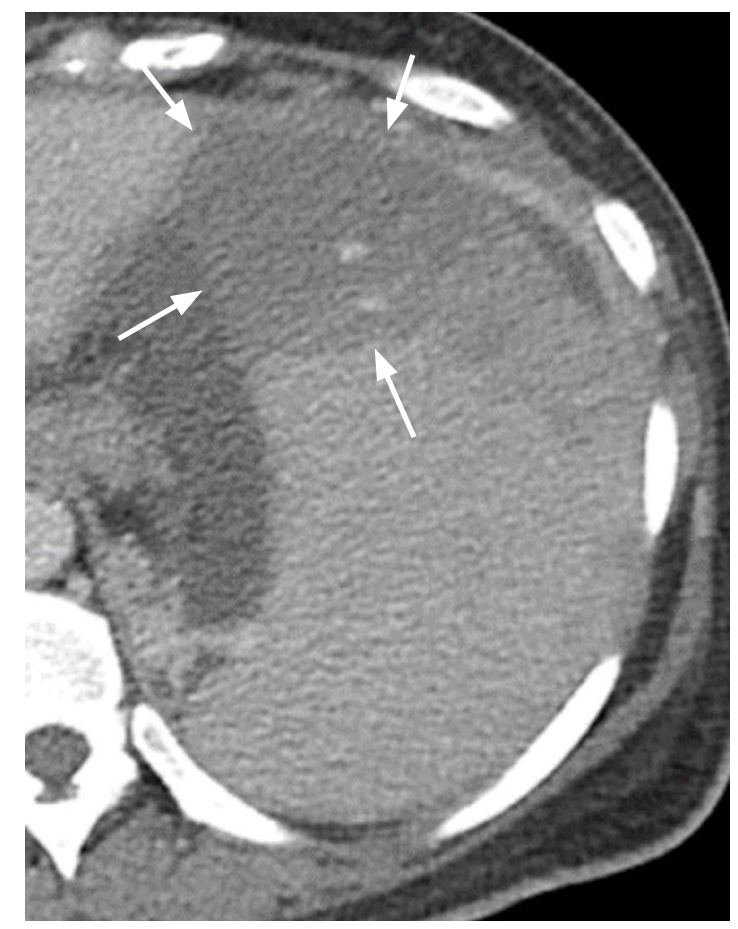

B

Fig. 19. A 41-year-old woman with splenic infarction and underlying liver cirrhosis and splenomegaly.

A. Longitudinal ultrasonography (US) of the spleen shows a well-defined hypoechoic area (arrows) in the enlarged spleen. B. Axial contrastenhanced computed tomography image shows a wedge-shaped hypoenhancing area (arrows) in the enlarged spleen, which matched the US findings. 


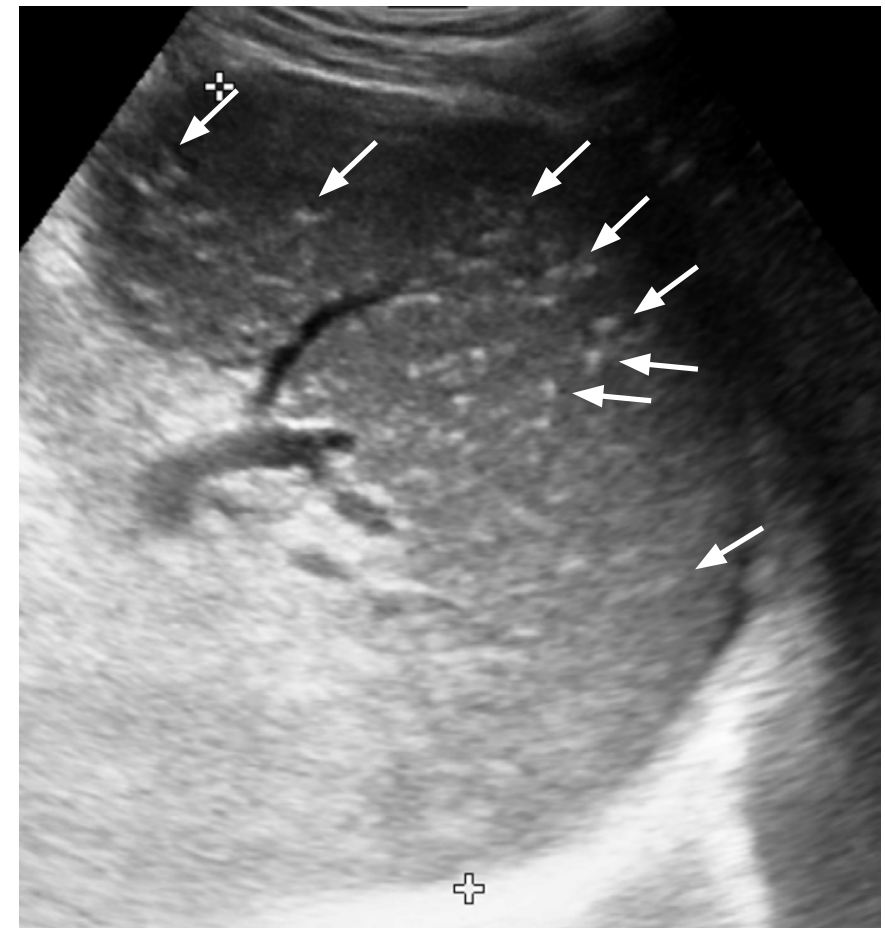

A

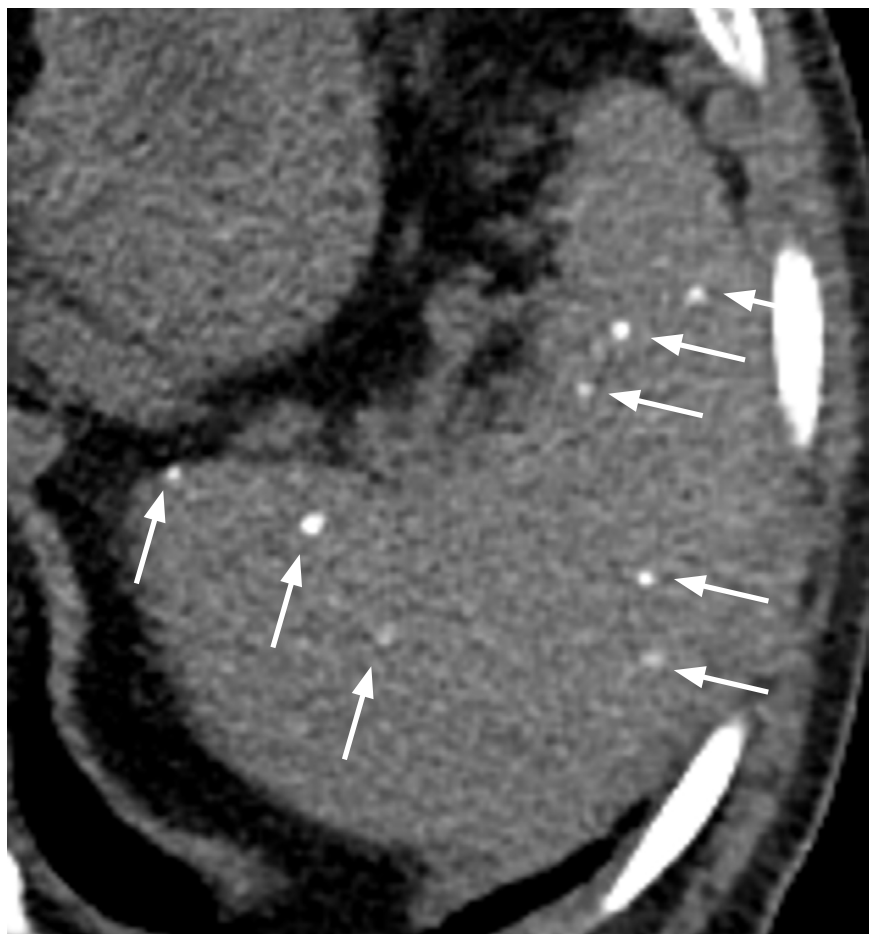

B

Fig. 20. A 63-year-old man with Gamna-Gandy bodies in the spleen.

A. Longitudinal ultrasonography of the spleen shows numerous scattered tiny punctate hyperechoic foci (arrows). B. Axial non-enhanced computed tomography image shows multiple tiny calcifications (arrows) in the spleen.

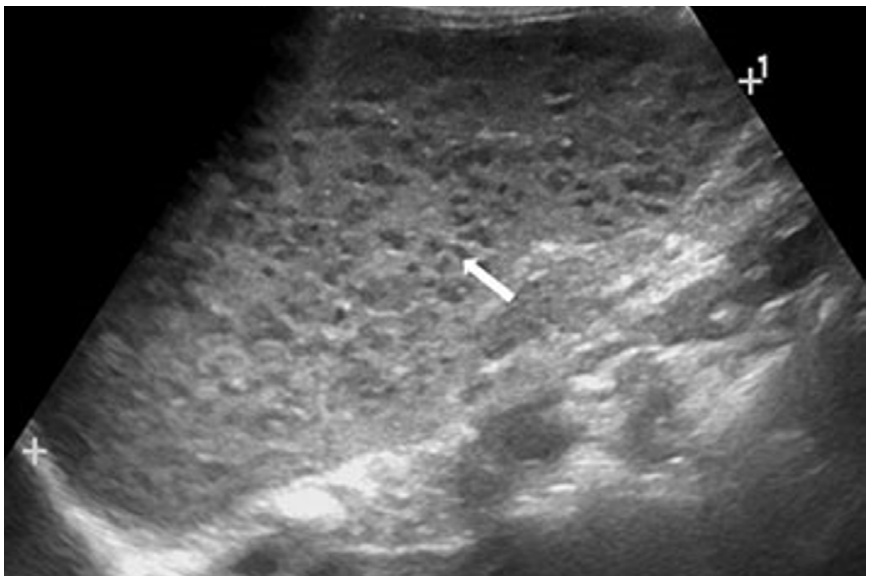

Fig. 21. A 3-year-old girl with splenic peliosis. Longitudinal ultrasonography of the spleen shows splenomegaly and multiple poorly defined hypoechoic nodules (arrow).

within the parenchyma [21]. While the liver is the most commonly affected organ, any organ can be involved, including the spleen. US shows multiple poorly defined hypoechoic lesions (Fig. 21) and hyperechoic thrombosis [12].

\section{Conclusion}

US of the spleen is readily performed as part of abdominal imaging, and the detection of splenic lesions is increasing. However, the differential diagnosis is challenging because a single disease category of the spleen can show various US findings, while many different splenic lesions have overlapping US findings. Table 2 presents a summary of the US findings of various splenic lesions. Most infectious and inflammatory lesions are seen as multiple small hypoechoic lesions, pyogenic abscesses have thick irregular walls, and parasitic infections typically show cystic lesions. Splenic hemangiomas have similar US features to hepatic hemangiomas. Hamartomas are typically isoechoic to hyperechoic on grayscale US and hypervascular on color Doppler US. Lymphangiomas are seen as thin-walled multilocular cysts. Lymphomas show various US features, ranging from solid nodules or masses to a miliary pattern and diffuse infiltration. Metastatic lesions in the spleen also show variable findings depending on the primary malignancy. Angiosarcoma shows splenomegaly with diffuse infiltration or multiple heterogeneous masses. Splenic infarction, for which various predisposing conditions have been identified, is seen as a wedgeshaped hypoechoic area. US examinations of the spleen can help 
narrow down the differential diagnosis and provide ancillary findings of the patient's condition. Moreover, US-guided biopsy of the target lesion in the spleen facilitates a minimally invasive and confirmative diagnosis.

Table 2. Summary of various splenic lesions on US

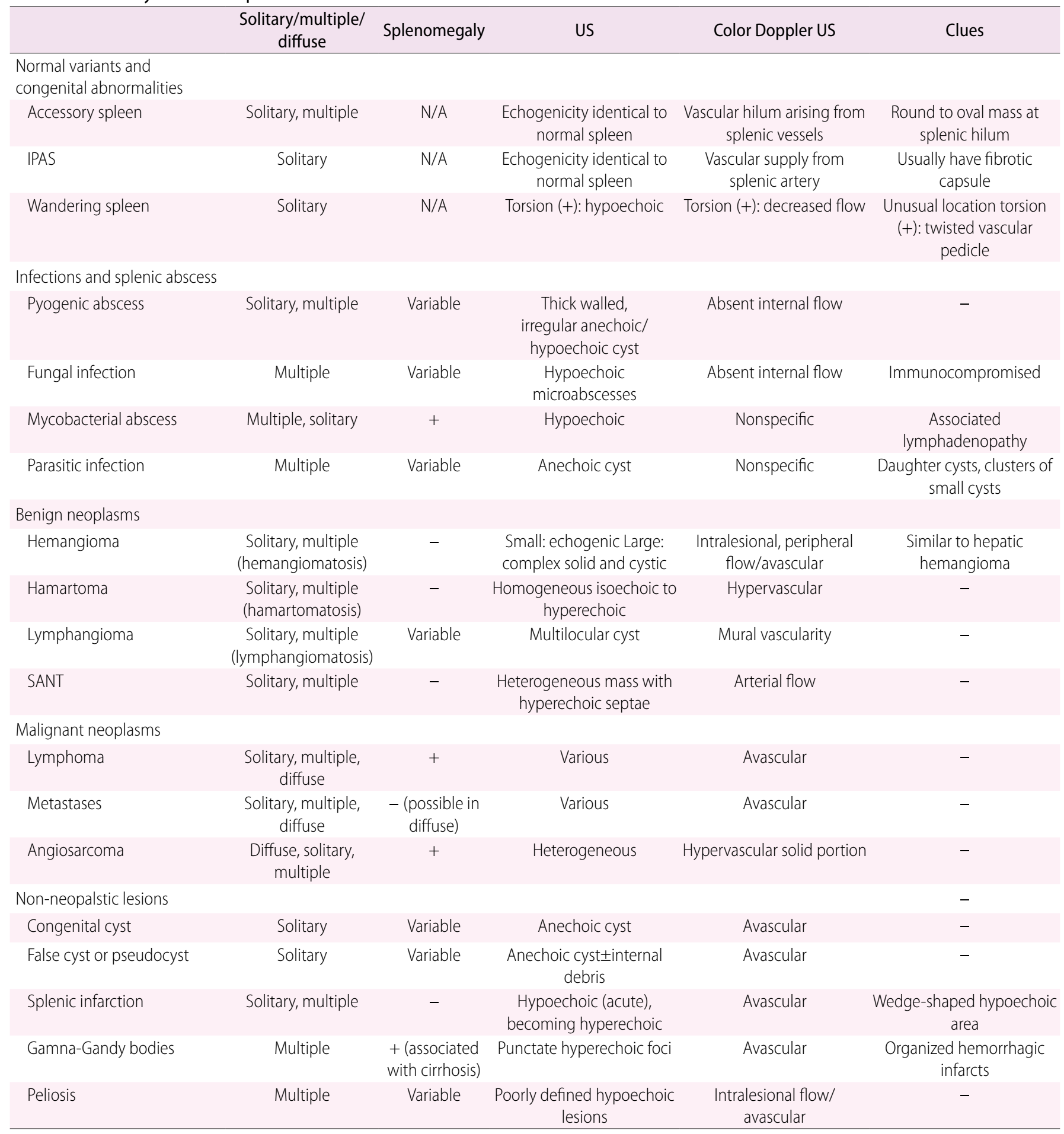

US, ultrasonography; N/A, not applicable; IPAS, intrapancreatic accessory spleen; SANT, sclerosing angiomatoid nodular transformation. 
ORCID: Gayoung Choi: https://orcid.org/0000-0002-2004-5228; Kyeong Ah Kim: https://orcid.org/0000-0003-4451-9325; Jinhwan Lee: https://orcid.org/0000-00033647-7487; Yang Shin Park: https://orcid.org/0000-0002-1918-2276; Jongmee Lee: https://orcid.org/0000-0002-6649-6120; Jae Woong Choi: https://orcid.org/00000001-5449-1560; Chang-Hee Lee: https://orcid.org/0000-0003-3381-2227

\section{Author Contributions}

Conceptualization: Choi G, Kim KA. Data acquisition: Choi G, Kim KA, Lee J, Park YS, Lee J, Choi JW, Lee CH. Data analysis or interpretation: Choi G, Kim KA, Lee J. Drafting of the manuscript: Choi G, Lee J. Critical revision of the manuscript: Choi G, Kim KA, Park YS, Lee J, Choi JW, Lee CH. Approval of the final version of the manuscript: all authors.

\section{Conflict of Interest}

No potential conflict of interest relevant to this article was reported.

\section{References}

1. Freeman SJ. Spleen. In: Allan PL, Baxter GM, Weston MJ, eds. Clinical ultrasound. 3rd ed. Edinburgh: Churchill Livingstone, 2011;324-347.

2. Thipphavong S, Duigenan S, Schindera ST, Gee MS, Philips S. Nonneoplastic, benign, and malignant splenic diseases: crosssectional imaging findings and rare disease entities. AJR Am J Roentgenol 2014;203:315-322.

3. Benter T, Kluhs L, Teichgraber U. Sonography of the spleen. J Ultrasound Med 2011;30:1281-1293.

4. Chen MJ, Huang MJ, Chang WH, Wang TE, Wang HY, Chu CH, et al. Ultrasonography of splenic abnormalities. World J Gastroenterol 2005;11:4061-4066.

5. Di Serafino M, Verde F, Ferro F, Vezzali N, Rossi E, Acampora C, et al. Ultrasonography of the pediatric spleen: a pictorial essay. J Ultrasound 2019;22:503-512.

6. Thomas S, Dachman AH. Spleen: normal anatomy and examination techniques. In: Gore RM, Levine MS, eds. Textbook of gastrointestinal radiology. 4th ed. Philadelphia, PA: Elsevier Saunders, 2015;1897-1904.

7. Thomas S, Dachman AH. Anomalies and anatomic variants of the spleen. In: Gore RM, Levine MS, eds. Textbook of gastrointestinal radiology. 4th ed. Philadelphia, PA: Elsevier Saunders, 2015;1912-
1922.

8. Subramanyam BR, Balthazar EJ, Horii SC. Sonography of the accessory spleen. AJR Am J Roentgenol 1984;143:47-49.

9. Urrutia M, Mergo PJ, Ros LH, Torres GM, Ros PR. Cystic masses of the spleen: radiologic-pathologic correlation. Radiographics 1996;16:107-129.

10. Kamaya A, Weinstein S, Desser TS. Multiple lesions of the spleen: differential diagnosis of cystic and solid lesions. Semin Ultrasound CT MR 2006;27:389-403.

11. Park YS, Lee $\mathrm{CH}$, Kim KA, Park CM. Imaging findings of splenic paragonimiasis: using contrast-enhanced ultrasonography. J Med Ultrasound 2013;21:36-38.

12. Abbott RM, Levy AD, Aguilera NS, Gorospe L, Thompson WM. From the archives of the AFIP: primary vascular neoplasms of the spleen: radiologic-pathologic correlation. Radiographics 2004;24:11371163.

13. Lewis RB, Lattin GE Jr, Nandedkar M, Aguilera NS. Sclerosing angiomatoid nodular transformation of the spleen: $\mathrm{CT}$ and MRI features with pathologic correlation. AJR Am J Roentgenol 2013;200:W353-W360.

14. Cao JY, Zhang H, Wang WP. Ultrasonography of sclerosing angiomatoid nodular transformation in the spleen. World J Gastroenterol 2010;16:3727-3730.

15. Chiorean L, Zdrenghea M, Badea R. Ultrasonography of the spleen. Pictorial essay. Med Ultrason 2014;16:48-59.

16. Caremani M, Occhini U, Caremani A, Tacconi D, Lapini L, Accorsi A, et al. Focal splenic lesions: US findings. J Ultrasound 2013;16:6574.

17. Peddu P, Shah M, Sidhu PS. Splenic abnormalities: a comparative review of ultrasound, microbubble-enhanced ultrasound and computed tomography. Clin Radiol 2004;59:777-792.

18. Paterson A, Frush DP, Donnelly LF, Foss JN, O'Hara SM, Bisset GS 3rd. A pattern-oriented approach to splenic imaging in infants and children. Radiographics 1999;19:1465-1485.

19. Goerg C, Schwerk WB. Splenic infarction: sonographic patterns, diagnosis, follow-up, and complications. Radiology 1990;174:803807.

20. Minami M, Itai Y, Ohtomo K, Ohnishi S, Niki T, Kokubo T, et al. Siderotic nodules in the spleen: MR imaging of portal hypertension. Radiology 1989;172:681-684.

21. Tsokos M, Erbersdobler A. Pathology of peliosis. Forensic Sci Int 2005; 149:25-33. 